\title{
Comparison of Multiparameter Flow Cytometry with Cluster Analysis and Immunohistochemistry for the Detection of CD10 in Diffuse Large B-Cell Lymphomas
}

\author{
Yin Xu, M.D., Ph.D., Robert W. McKenna, M.D., Steven H. Kroft, M.D. \\ Department of Pathology, University of Texas Southwestern Medical Center, Dallas, Texas
}

\begin{abstract}
CD10 is a critical antigen for the distinction of folliclecenter lymphoma from other B-cell lymphomas composed of small cells in fine-needle aspiration specimens, tissue core biopsies, and bone marrow. In addition, CD10 is expressed in a subset of diffuse large B-cell lymphomas (DLBCLs), where it may be an adverse prognostic indicator. We have previously demonstrated that CD10 expression detected by multiparameter flow cytometry (FC) with cluster analysis is highly sensitive and specific for follicle-center lymphoma in the differential diagnosis of small B-cell lymphomas. In this study, we assessed the utility of paraffin section immunohistochemistry (IHC) for CD10 compared with FC in a cohort of 50 DLBCLs. IHC for CD10 was technically successful in 47 of the 50 (94\%) DLBCLs; 3 failed based on lack of internal CD10 reactivity. CD10 was expressed by FC in 20 of $47 \mathrm{DL}-$ BCLs (43\%); CD10 was positive by IHC in 15 of these (75\%). All 27 cases that were $\mathrm{CD10}(-)$ by $\mathrm{FC}$ were negative by IHC. The level of CD10 expression by FC in the $5 \mathrm{FC}(+) / \mathrm{IHC}(-)$ cases ranged from relatively dim to bright. Our results indicate $75 \%$ sensitivity and $100 \%$ specificity of CD10 expression by IHC compared with multiparameter FC with cluster analysis and a $6 \%$ technical failure rate.
\end{abstract}

KEY WORDS: CD10, Diffuse large B-cell lymphoma, Flow cytometry, Immunohistochemistry, Immunophenotyping, Non-Hodgkin's lymphoma.

Mod Pathol 2002;15(4):413-419

CD10 is a cell-surface glycoprotein with neutral endopeptidase activity $(1,2)$. It is expressed in a variety of normal and neoplastic hematolymphoid cells, including lymphoid precursors, germinal center B lymphocytes, and granulocytes $(3,4)$. Al-

Copyright (C) 2002 by The United States and Canadian Academy of Pathology, Inc.

VOL. 15, NO. 4, P. 413, 2002 Printed in the U.S.A.

Date of acceptance: December 20, 2001

Address reprint requests to: Steven H. Kroft, M.D., Department of Pathology, University of Texas Southwestern Medical Center, 5323

Harry Hines Blvd., Dallas, TX 75390-9073; fax: 214-590-6667; e-mail: kroft.steven@pathology.swmed.edu. though CD10 is not lineage specific, it is a useful marker in the differential diagnosis of B-cell lymphomas, because it is expressed on the vast majority of follicle-center lymphomas and Burkitt lymphomas and in a subset of diffuse large B-cell lymphomas (DLBCL; 5). The function of CD10 in the B-cell lymphomas is not well defined. We and others have recently identified that CD10 expression on DLBCL may be associated with an unfavorable clinical course $(6,7)$.

CD10 can be reliably detected by multiparameter flow cytometry (FC) with cluster analysis with a sensitivity of $98 \%$ and specificity of $95 \%$ for the differential diagnosis of low-grade follicle-center lymphoma from other small B-cell lymphomas (8). Recently, paraffin-reactive antibodies for CD10 have become commercially available (9). Immunohistochemistry (IHC) for CD10 is a practical method that is of particular value in retrospective studies of CD10 expression in paraffin-embedded tissue. However, the performance characteristics of paraffin-reactive CD10 antibodies in non-Hodgkin's lymphoma have not been extensively studied. The present study was designed to compare IHC with FC in the detection of CD10 in a cohort of DLBCLs.

\section{MATERIALS AND METHODS}

\section{Case Selection}

Fifty consecutive cases of DLBCL with available histologic sections and paraffin-embedded tissue blocks were retrieved from the clinical flow cytometry database at the University of Texas Southwestern Medical Center from April 1994 to July 1999.

\section{Flow Cytometry}

Fresh biopsy tissue was sliced and disaggregated through a $<100-\mu \mathrm{m}$ mesh, and cells were suspended in 5\% newborn calf serum in RPMI 1640 tissue culture medium (Life Technology, Rockville, MD). Cell counts were performed manually, and 500,000 cells per tube were washed with a solution of phosphate buffered 
saline (PBS), $0.0455 \%$ sodium azide, and $0.1 \%$ bovine serum albumin and then incubated with either a three-color or four-color combination of antibodies. Antibodies against CD2(55.2), CD3(SK7), CD4(SK3), CD5(L17F12), CD7(4H9), CD8(SK1), CD10(W8E7), CD19(SJ25C1), CD20(L27), CD38(HB7), CD45(2D1), CD45RO(UCHL-1), and monoclonal $\kappa($ TB28-2) and $\lambda$ (I-155-2) immunoglobulins were obtained from Becton Dickinson (San Jose, CA). Antibodies against FMC7(FMC7), CD23(B6), and polyclonal immunoglobulin kappa (goat) and lambda (goat) were obtained from Coulter-Immunotech (Hialeah, FL). Anti-CD30(BerH2) was obtained from DAKO (Carpinteria, CA). These antibodies were conjugated with fluorescein isothiocyanate (FITC), phycoerythrin, peridinin chlorophyll protein, or allophycocyanin. CD10 expression was determined using one of the following antibody combinations: CD10-FITC-CD38-phycoerythrinCD20-peridinin chlorophyll protein or CD10FITC-CD19-phycoerythrin-CD20-peridinin chlorophyll protein-CD38-allophycocyanin. Twenty microliters of CD10 antibody was used; this amount was determined by previous titration studies. Specimens were incubated at $2-8^{\circ} C$ in the dark for 20 minutes; washed with a solution of PBS, $0.0455 \%$ sodium azide, and $0.1 \%$ bovine serum albumin; and resuspended in $1 \%$ paraformaldehyde in PBS. Flow-cytometric data were acquired using three-color FACScan or four-color FACSCalibur flow cytometry instruments with CELLQuest software (Becton Dickinson). Data analysis was performed using Paint-a-Gate software (Becton Dickinson). Nonviable-cells and debris were excluded based on forward and orthogonal light scatter properties. Antigen expression was assessed as an overt qualitative shift of the tumor cell population relative to the same population identified by scatter characteristics in an isotypic control tube. In equivocal cases, positivity was defined as $10 \%$ of lymphoma events beyond a $2 \%$ threshold, based on the same population in an isotypic control tube. Granulocytes were used as an internal CD10-positive control.

\section{Histology and Immunohistochemistry}

Initial diagnostic biopsies were fixed in B5 fixative and/or $10 \%$ neutral buffered formalin, embedded in paraffin, and sectioned at $3 \mu \mathrm{m}$. Sections were stained with hematoxylin and eosin for morphologic evaluation.

Immunohistochemistry was performed on the paraffin sections (29 B5 fixed and 21 formalin fixed) with monoclonal anti-CD10 (56C6, Vector, Burlingame, CA) using a TechMate automated immunostainer (Ventana Biotek, Tucson, AZ) and a streptavidin-biotin peroxidase detection system. For antigen retrieval, sections were placed in $200-\mathrm{mL}$ of Antigen Retrieval Citrate buffer (BioGenex, San Ramon, CA), pH 6.8, and boiled for 5 minutes. After adding $50 \mathrm{~mL}$ of deionized water, the buffer was again brought to a boil for 5 minutes. The slides were allowed to cool in buffer for 20 minutes before further processing. CD10 expression by IHC was evaluated without knowledge of the results of flowcytometric CD10 phenotype. IHC was considered to be successful if internal control cells (granulocytes, fibroblasts, or myoepithelial cells) exhibited CD10 reactivity. Cases were scored as positive if $>5 \%$ of the lymphoma cells exhibited cytoplasmic or membrane staining.

\section{RESULTS}

\section{CD10 Expression by FC}

All cases consisted of a population of neoplastic large B cells with restricted immunoglobulin light chain expression or lack of surface light chains by three- or four-color flow cytometry. Analysis of CD10 expression by FC is illustrated in Figure 1. Of the 50 cases, $22(44 \%)$ were $\mathrm{CD} 10(+)$, and $28(56 \%)$, CD10(-). Large lymphoma cells often showed higher background staining than did small lymphocytes. This effect is largely caused by cellular autofluorescence (data not shown). Some DLBCLs with a CD10 fluorescence shift of the tumor population relative to nonneoplastic $\mathrm{B}$ lymphocytes were seen to be $\mathrm{CD} 10(-)$ when compared with the tumor population in the isotypic control tube (Fig. 2).

\section{CD10 Expression by IHC}

Forty-seven of fifty cases (94\%) were successfully evaluated by IHC; three cases failed IHC based on lack of internal CD10 reactivity in granulocytes or other cells ( 1 fixed in B5 and 2 fixed in formalin; Fig. 3). Fifteen cases (32\%) were CD10(+), and $32(68 \%)$, CD10- - . The CD10-staining pattern appeared to be mainly cytoplasmic and varied from patchy to diffuse (Fig. 3). At least $10 \%$ of tumor cells exhibited reactivity in all $\mathrm{CD} 10(+)$ cases. All $\mathrm{CD} 10(-)$ cases showed no positive staining in any tumor cells, but reactivity was observed in internal control cells such as granulocytes, fibroblasts, and myoepithelial cells (Fig. 3).

\section{Comparison of CD10 Expression by FC and IHC}

The results of IHC and FC are compared in Table 1. Five of 49 cases $(11 \%)$ showed discordance between CD10 expression by FC and IHC; all 5 were IHC $(-) / F C(+)$. CD10 was positive by IHC in 15 of the 20 FC-positive cases $(75 \%$ sensitivity compared with FC). All 27 cases that were CD10(-) by IHC were negative by FC $(100 \%$ specificity com- 

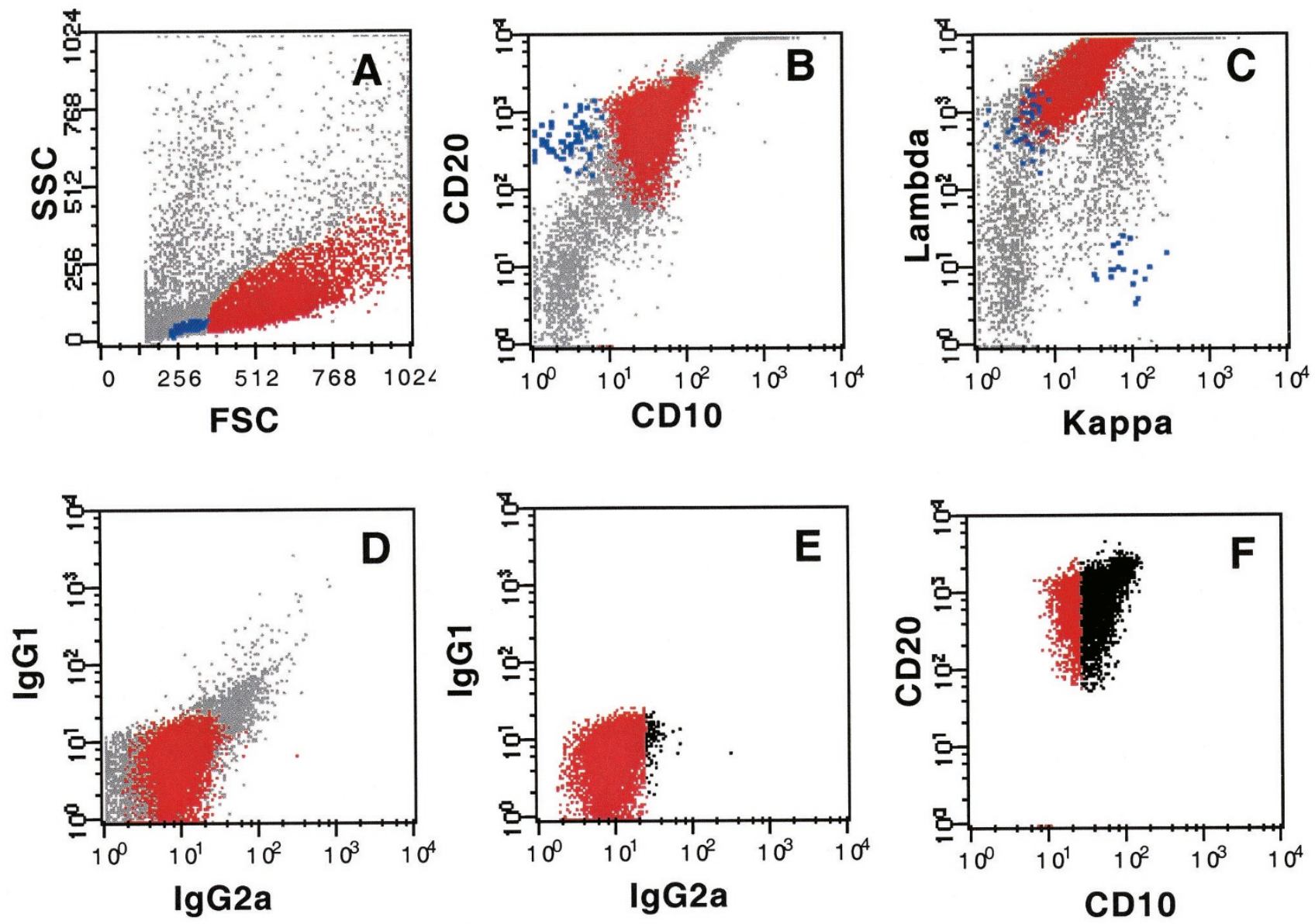

FIGURE 1. Analysis of CD10 expression by multiparameter flow cytometry with cluster analysis. A, cell distribution by forward and orthogonal light scatter. Red population, lymphoma cells; blue population, nonneoplastic B lymphocytes. B-C, tumor cells are CD20(+), CD10(+), and Ig lightchain restricted. D, tumor cells identified by scatter properties in the isotypic control tube. E, the threshold for CD10 in the isotypic control is set with a cutoff of $2 \%$ tumor cells (painted in black). F, a discrete shift of the entire tumor cluster indicating uniform CD10 expression on the tumor cells. Events beyond the CD10 threshold are in black.

pared with FC). The five $\operatorname{IHC}(-) / \mathrm{FC}(+)$ cases showed variable CD10 levels by FC, ranging from relatively dim to bright (Fig. 4); three of these cases were B5 fixed, and two were formalin fixed.

\section{DISCUSSION}

CD10 is a key molecule in the classification of B-lineage lymphomas and characterization of acute leukemias $(3,5,10)$. Reliable detection of CD10 expression is of great value in diagnosis and prognostic assessment in hematolymphoid neoplasms. In the past, anti-CD10 antibodies were useful only in frozen-section immunophenotyping and flow cytometry; they lacked reactivity in fixed paraffinembedded tissue (3). Recently, CD10 immunostaining in paraffin-embedded tissue has been achieved with a newly generated monoclonal antibody (56C6; 9), which has been proven to be reactive with various cell types including renal tubules, glomeruli, brush borders of the intestine, hepatic canaliculi, syncytiotrophoblasts, and lymphoid germinal centers (9). MAb 56C6 has also been shown to be immunoreactive with a variety of neoplasms such as renal cell carcinoma, transitional cell carcinoma, prostatic adenocarcinoma, endometrial stromal sarcoma, rhabdomyosarcoma, pancreatic adenocarcinoma, schwannoma, and malignant melanoma (11). In addition, the antibody is effective in detection of CD10 on a range of hematolymphoid neoplasms (12-16), but its utility in lymphomas has not been extensively studied.

CD10 is expressed in a subset of DLBCL, a heterogeneous group of non-Hodgkin's lymphomas (6, $7,17,18$ ). The majority of DLBCL patients can be cured with current treatment regimens, whereas a minority fail to achieve complete remission and rapidly progress to death. Therefore, studies have been undertaken to identify markers to dissect DLBCL into distinct biologic categories. CD10 expression in DLBCL has been shown to correlate with bcl-2 gene rearrangement in a single study (17); however, bcl-2 protein expression rather than bcl-2 translocation affects patient survival (19-22). We have recently demonstrated that $\mathrm{CD} 10(+)$ de novo DLBCL is associated with a significantly lower rate 


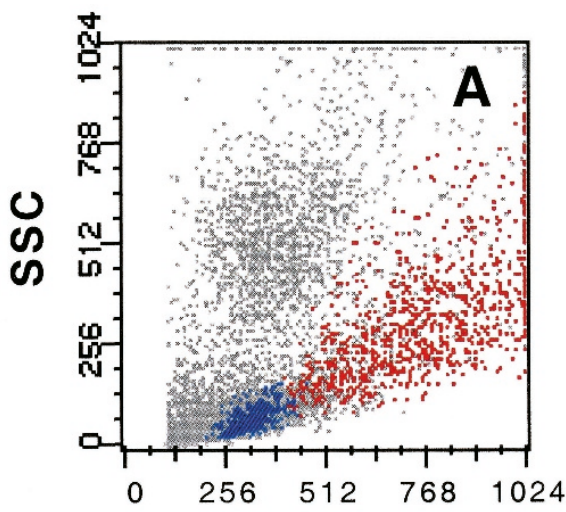

FSC

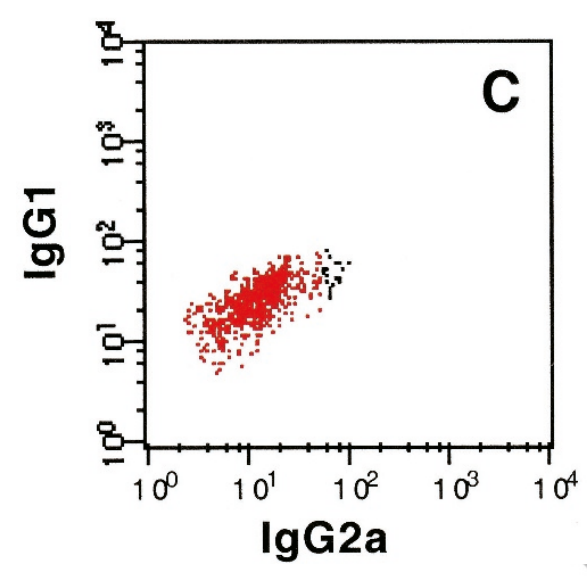

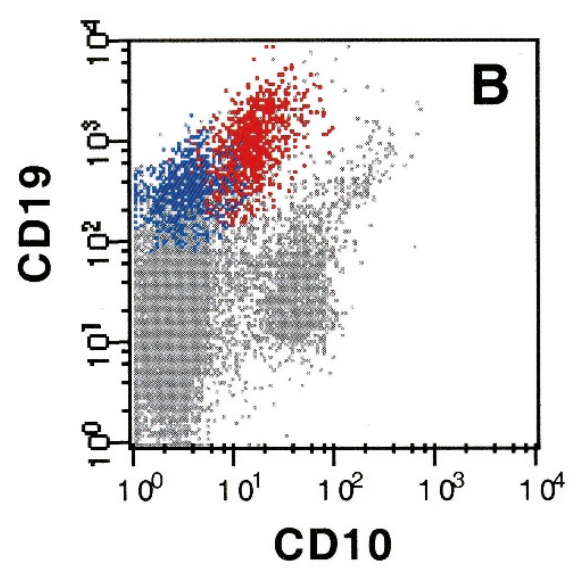

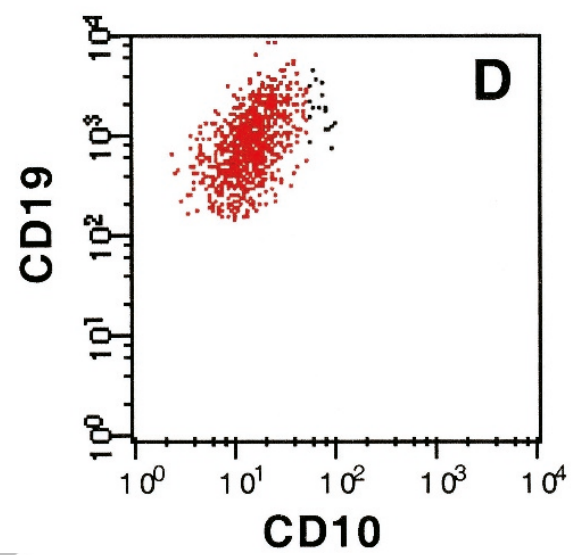

FIGURE 2. Increased nonspecific fluorescence on large lymphoma cells compared with small B cells in a CD10(-) diffuse large B-cell lymphoma case. A, cell distribution by forward and orthogonal light scatter. B, relative shift of tumor cells (red) to nonneoplastic B lymphocytes (blue) by CD10-fluorescein isothiocyanate fluorescence intensity. C, setting threshold for CD10 in tumor population in the isotypic control tube. D, lack of CD10 expression by tumor cells compared with the isotypic control.

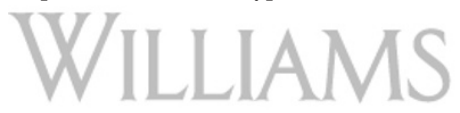

of complete remission, whereas $\mathrm{CD} 10(+)$ and CD10(-) DLBCLs are similar with regard to a variety of other clinical and pathologic features (6). Furthermore, we demonstrated that patients with dual CD10(+)/bcl-2(+) tumors showed a markedly worse complete remission rate and overall survival (6). Similarly, Uherova et al. (7) reported that CD10 expression in DLBCL correlated with shortened overall survival. In contrast, Harada et al. (18) found no difference in overall survival between $\mathrm{CD10}(+)$ and CD10(-) DLBCL patients. The availability of paraffin-reactive antibodies directed against CD10 suggests that retrospective studies with fixed tissue may be possible to confirm the prognostic significance of CD10 on DLBCL.

In the present study, we demonstrated that IHC with MAb 56C6 is $100 \%$ specific for CD10 detection in a series of DLBCL compared with multiparameter FC. However, IHC is only $75 \%$ sensitive for CD10 compared with FC. A potential explanation for this difference is a lower detection threshold of FC compared with IHC, whereby dim antigen expression may be easily distinguished from background. However, the broad range of CD10 expres-

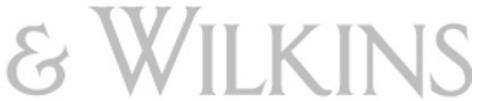

sion by FC in the IHC(-) cases in the current study does not support this hypothesis. Alternatively, CD10 epitope recognition by MAb 56C6 may be less stable in lymphoma cells than in other cell types in fixed tissue. IHC worked well in our laboratory based on CD10 reactivity in internal tissue controls, with a $94 \%$ technical success rate. The failures in CD10 IHC are most likely related to fixation issues. However, data regarding time and length of fixation in these cases are not available because of the retrospective nature of this study. It is well known that differences in fixation and antigen retrieval may have a large impact on the performance of IHC stains. For example, overfixation in B5 may result in nonspecific staining (23).

A few studies have addressed the utility of paraffin-section IHC for the detection of CD10. Kurtin et al. (14) demonstrated that IHC agreed with FC-frozen-section immunoperoxidase satin (FSIP) in $80 \%$ of low-grade follicle-center lymphomas. In their series, $92 \%$ of follicle-center lymphomas expressed CD10 by IHC. Among the 20 cases with available FC-FSIP results for comparison, 18 were $\mathrm{CD} 10(+)$ by IHC, and 16 were $\mathrm{CD} 10(+)$ by FC-FSIP. 

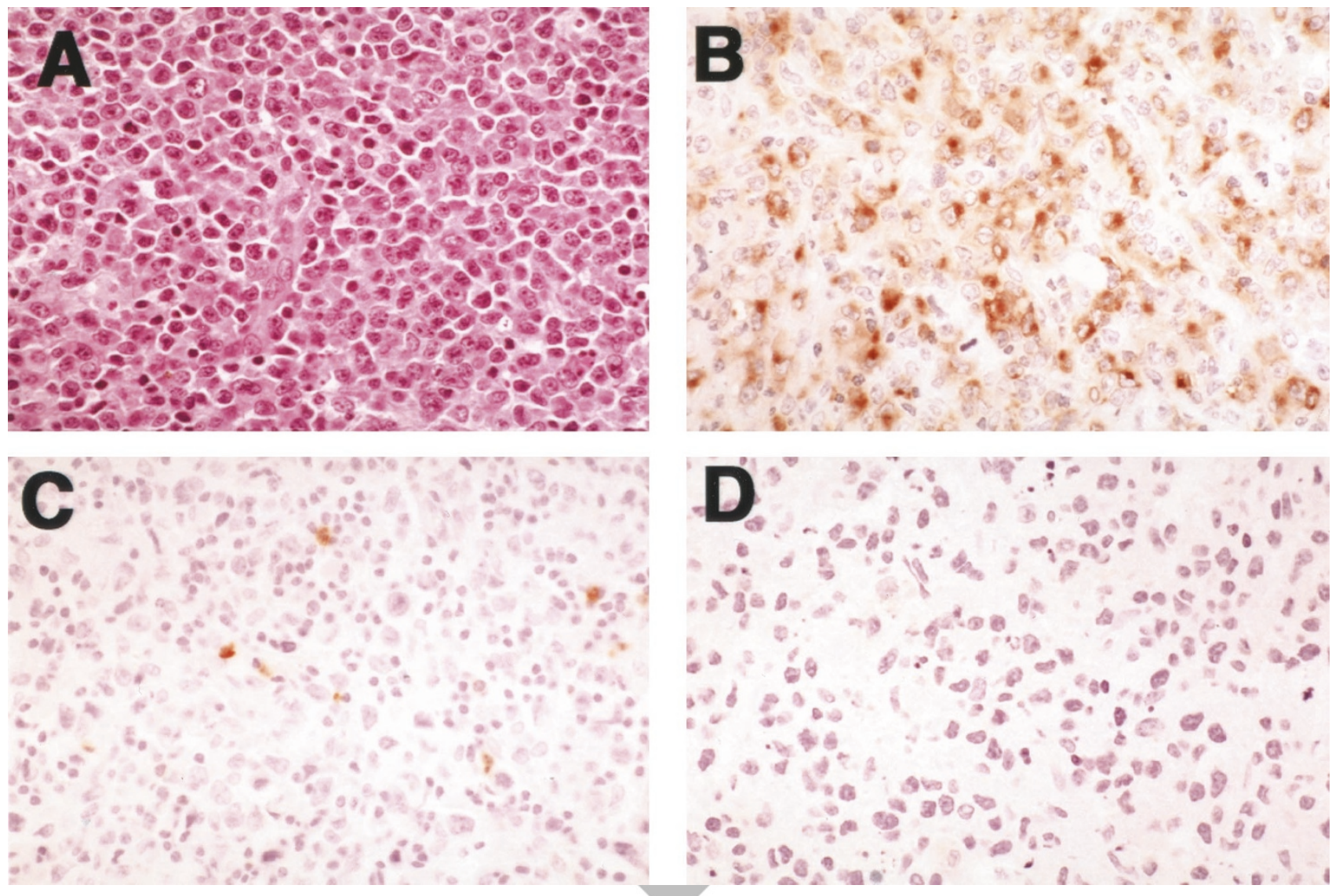

FIGURE 3. Detection of CD10 on diffuse large B-cell lymphoma (DLBCL) by immunohistochemistry (IHC) with MAb 56C6. A, a representative DLBCL case on hematoxylin and eosin section. B, positive CD10 IHC in a DLBCL case. C, negative CD10 IHC in a DLBCL case with CD10 staining of granulocytes. D, technical failure of CD10 IHC based on lack of a CD10 staining of internal controls.

IVI

TABLE 1. Summary of Results of CD10 Detection by Flow Cytometry (FC) and Immunohistochemistry (IHC)

\begin{tabular}{crcc}
\hline $\begin{array}{c}\text { Flow Cytometry } \\
\text { Result }\end{array}$ & $\mathrm{IHC}(+)$ & $\mathrm{IHC}(-)$ & Technical Failure \\
\hline Positive & 15 & 5 & 2 \\
Negative & 0 & 27 & 1 \\
\hline
\end{tabular}

It is possible that IHC is more sensitive for CD10 detection in low-grade FCL than is DLBCL.

A high correlation of CD10 detection between IHC and FC (98\%) in acute leukemia was reported by Bavikatty et al. (12). The high density of CD10 antigen on most precursor B-cell acute lymphoblastic leukemias may enhance the antigen detection by IHC. On the other hand, there may be some cell type-related variability of antigen recognition. For example, CD10 epitopes on large lymphoma cells may be less stable and retrievable. Different molecular forms of CD10 cDNAs and proteins are found in different cell types (24-28). However, the stability of CD10 protein in different cell types has not been investigated. Finally, the discrepancies of CD10 IHC sensitivity between our results and others may represent greater sensitivity of our three- or

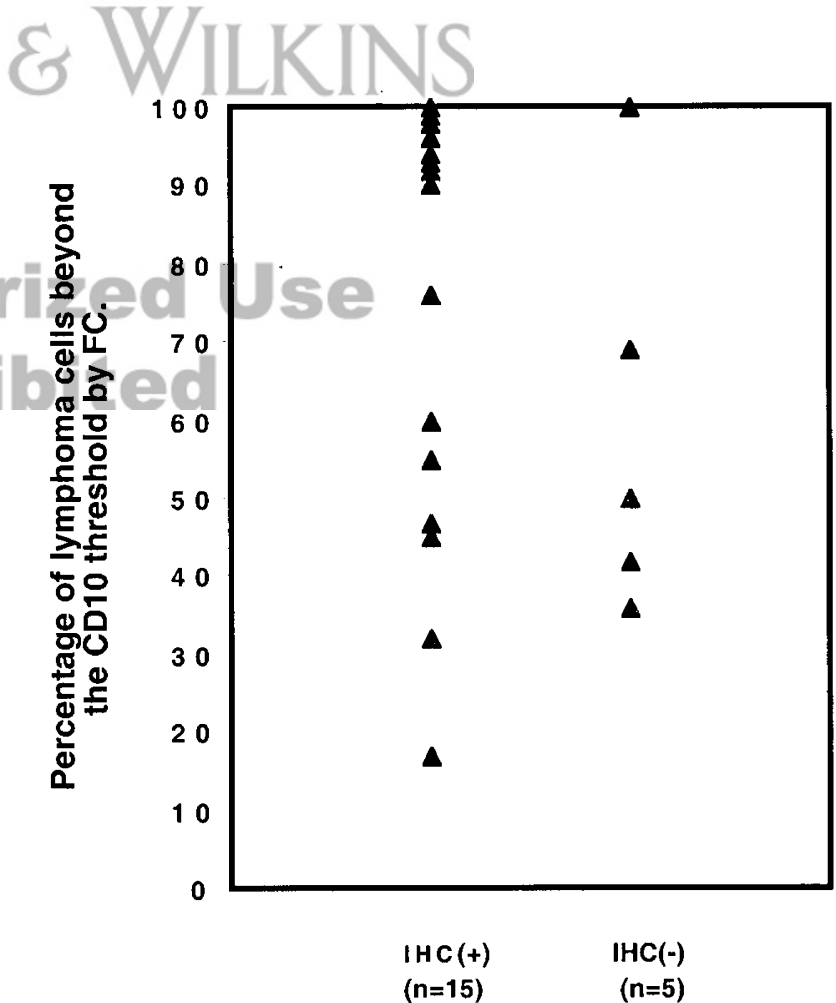

FIGURE 4. $\mathrm{CD} 10(+)$ case by flow cytometry: comparison of percentage of lymphoma cells beyond isotypic CD10 threshold. 
four-color flow cytometry techniques using isotypic controls and cluster analysis. In our laboratory, we have demonstrated that CD10 expression can be successfully detected in $98 \%$ of low-grade folliclecenter lymphomas (8). Kaufmann et al. (13) investigated CD10 IHC in 174 cases of hematolymphoid neoplasms, including B- and T-cell lymphomas and acute leukemias. They found one case with discordant result $[\operatorname{IHC}(-), F C(+)]$ among 32 cases in which CD10 detection by IHC was compared with FC. However, it was not clear how many of these cases were lymphomas. Chu et al. (29) reported a high correlation of flow cytometry with IHC for CD10 detection in a series of 56 hematopoietic neoplasms, although no DLBCL cases were included in this study.

An additional practical point illustrated in this study is the observation that large lymphoma cells often have higher nonspecific fluorescence than do small cells by FC, producing a potential pitfall in interpretation. This phenomenon appears to be largely due to cellular autofluorescence. Therefore, comparison of fluorescence intensity with an internal negative population is insufficient for immunophenotypic characterization of large B-cell lymphomas. Careful comparison of CD10 expression on large cells with the same population in an isotypic control tube is necessary for accurate interpretation. We have also encountered this phenomenon in other neoplastic processes composed of large cells (e.g., acute myeloid leukemia, anaplastic largecell lymphoma).

In conclusion, we demonstrated that $\mathrm{CD} 10 \mathrm{IHC}$ is highly specific for CD10 detection in DLBCL compared with FC, but it is less sensitive. These findings have implications for the use of CD10 IHC in the identification of large B-cell lymphomas of follicular origin.

\section{REFERENCES}

1. Letarte M, Vera S, Tran R, Addis JB, Onizuka RJ, Quackenbush EJ, et al. Common acute lymphocytic leukemia antigen is identical to neutral endopeptidase. J Exp Med 1988;168: 1247-53.

2. Shipp MA, Look AT. Hematopoietic differentiation antigens that are membrane-associated enzymes: cutting is the key! Blood 1993;82:1052-70.

3. Arber DA. CD10: a review. Appl Immunohistochem 1997;5: $125-40$.

4. LeBien TW, McCormack RT. The common acute lymphoblastic leukemia antigen (CD10)-emancipation from a functional enigma. Blood 1989;73:625-35.

5. Harris NL, Jaffe ES, Stein H, Banks PM, Chan JK, Cleary ML, et al. A revised European-American classification of lymphoid neoplasms: a proposal from the International Lymphoma Study Group. Blood 1994;84:1361-92.

6. Xu Y, McKenna RW, Molberg KH, Kroft SH. Clinicopathologic analysis of $\mathrm{CD} 10+$ and $\mathrm{CD} 10-$ diffuse large B-cell lymphoma. Identification of a high-risk subset with coex- pression of CD10 and bcl-2. Am J Clin Pathol 2001;116:18390.

7. Uherova PRC, Schnitzer B, Singleton TP, Finn WG. The clinical significance of CD10 antigen expression in diffuse large B-cell lymphoma. Am J Clin Pathol 2000;115:582-8.

8. Xu YMR, Kroft SH. Assessment of CD10 in the diagnosis of small B-cell lymphomas: a multiparameter flow cytometric study. Am J Clin Pathol 2002;117:291-300.

9. McIntosh GG, Lodge AJ, Watson P, Hall AG, Wood K, Anderson JJ, et al. NCL-CD10-270: a new monoclonal antibody recognizing CD10 in paraffin-embedded tissue. Am J Pathol 1999;154:77-82.

10. Uckun FM, Sather H, Gaynon P, Arthur D, Nachman J, Sensel $\mathrm{M}$, et al. Prognostic significance of the CD10+CD19+CD34+ B-progenitor immunophenotype in children with acute lymphoblastic leukemia: a report from the Children's Cancer Group. Leuk Lymphoma 1997;27:445-57.

11. Chu P, Arber DA. Paraffin-section detection of CD10 in 505 nonhematopoietic neoplasms. Frequent expression in renal cell carcinoma and endometrial stromal sarcoma. Am J Clin Pathol 2000;113:374-82.

12. Bavikatty NR, Ross CW, Finn WG, Schnitzer B, Singleton TP. Anti-CD10 immunoperoxidase staining of paraffinembedded acute leukemias: comparison with flow cytometric immunophenotyping. Hum Pathol 2000;31:1051-4.

13. Kaufmann O, Flath B, Spath-Schwalbe E, Possinger K, Dietel M. Immunohistochemical detection of CD10 with monoclonal antibody 56C6 on paraffin sections. Am J Clin Pathol 1999;111:117-22.

14. Kurtin PJ, Hobday KS, Ziesmer S, Caron BL. Demonstration of distinct antigenic profiles of small B-cell lymphomas by paraffin section immunohistochemistry. Am J Clin Pathol 1999;112:319-29.

15. Conde-Sterling DA, Aguilera NS, Nandedkar MA, Abbondanzo SL. Immunoperoxidase detection of CD10 in precursor T-lymphoblastic lymphoma/leukemia: a clinicopathologic study of 24 cases. Arch Pathol Lab Med 2000;124:704-8.

16. Watson P, Wood KM, Lodge A, McIntosh GG, Milton I, Piggott $\mathrm{NH}$, et al. Monoclonal antibodies recognizing CD5, CD10 and CD23 in formalin-fixed, paraffin-embedded tissue: production and assessment of their value in the diagnosis of small B-cell lymphoma. Histopathology 2000;36: 145-50.

17. Fang JM, Finn WG, Hussong JW, Goolsby CL, Cubbon AR, Variakojis D. CD10 antigen expression correlates with the $t(14 ; 18)$ (q32;q21) major breakpoint region in diffuse large B-cell lymphoma. Mod Pathol 1999;12:295-300.

18. Harada S, Suzuki R, Uehira K, Yatabe Y, Kagami Y, Ogura M, et al. Molecular and immunological dissection of diffuse large B cell lymphoma: CD5+, and CD5- with CD10+ groups may constitute clinically relevant subtypes. Leukemia 1999;13:1441-7.

19. Gascoyne RD, Adomat SA, Krajewski S, Krajewska M, Horsman $\mathrm{DE}$, Tolcher AW, et al. Prognostic significance of Bcl-2 protein expression and Bcl-2 gene rearrangement in diffuse aggressive non-Hodgkin's lymphoma. Blood 1997;90:244-51.

20. Hill ME, MacLennan KA, Cunningham DC, Vaughan Hudson B, Burke M, Clarke P, et al. Prognostic significance of BCL-2 expression and bcl-2 major breakpoint region rearrangement in diffuse large cell non-Hodgkin's lymphoma: a British National Lymphoma Investigation Study. Blood 1996;88: 1046-51.

21. Kramer MH, Hermans J, Wijburg E, Philippo K, Geelen E, van Krieken JH, et al. Clinical relevance of BCL2, BCL6, and MYC rearrangements in diffuse large B-cell lymphoma. Blood 1998;92:3152-62.

22. Skinnider BF, Horsman DE, Dupuis B, Gascoyne RD. Bcl-6 and $\mathrm{Bcl}-2$ protein expression in diffuse large B-cell lymphoma and 
follicular lymphoma: correlation with 3q27 and 18q21 chromosomal abnormalities. Hum Pathol 1999;30:803-8.

23. Warnke RA, Isaacson PG. Immunohistochemical analysis of lymphoid tissue. In: Knowles DM, editor. Neoplastic hematopathology. 2nd ed. New York: Lippincott Williams \& Wilkins; 2001. p. 227-53.

24. Metzgar RS, Borowitz MJ, Jones NH, Dowell BL. Distribution of common acute lymphoblastic leukemia antigen in nonhematopoietic tissues. J Exp Med 1981;154:1249-54.

25. Braun MP, Martin PJ, Ledbetter JA, Hansen JA. Granulocytes and cultured human fibroblasts express common acute lymphoblastic leukemia-associated antigens. Blood 1983;61:718-25.

26. D’Adamio L, Shipp MA, Masteller EL, Reinherz EL. Organization of the gene encoding common acute lymphoblastic leukemia antigen (neutral endopeptidase 24.11): multiple miniexons and separate 5 ' untranslated regions. Proc Natl Acad Sci U S A 1989;86:7103-7.

27. Haouas H, Morello D, Lavenu A, Billard M, Jasmin C, Boucheix C. Characterization of the 5 ' region of the $\mathrm{CD} 10 /$ neutral endopeptidase 24.11 gene. Biochem Biophys Res Commun 1995;207:933-42.

28. Ishimaru F, Shipp MA. Analysis of the human CD10/neutral endopeptidase 24.11 promoter region: two separate regulatory elements. Blood 1995;85:3199-207.

29. Chu PG, Chang KL, Weiss LM, Arber DA. Immunohistochemical detection of CD10 in paraffin sections of hematopoietic neoplasms: a comparison with flow cytometry detection in 56 cases. Appl Immunohistochem Mol Morphol 2000; 8:257-62.

\section{Book Review}

Young B: Picture Tests in Histology, 248 pp, London, Churchill Livingstone, 2001 (\$24.95).

Picture Tests in Histology is a collection of questions keyed to about 120 color photomicrographs and electron micrographs developed by Dr. Barbara Young. Dr. Young is an accomplished anatomic pathologist who has authored two other books: Wheater's Functional Histology and Wheater's Histopathology. This new picture test book is a companion to Wheater's Functional Histology (Young and Heath). The questions and accompanying photo and electron micrographs are organized into five tests with feedback provided at the end of each of those units. The focus is to provide a mechanism for the student to prepare for examinations or complete a quick review of basic histology.

In general, the quality of the tissue selected and the micrographs is good-to-excellent. There is a good balance between light and electron micrographs. The use of true and false questions allows students to go through the material quickly and identify deficits in their knowledge, but it is not a format used for USMLE Step I or on most medical school exams. The feedback for the questions is adequate but often too limited, containing only histology material. The author does not take advantage of the opportunity to inte- grate structure and function and to include important cell biological information in the explanations. The division into five tests rather than subject areas is also awkward.

The main question is what would be the market for such a text? I see little interest among medical students. Many schools have Websites or CDs with similar or better photomicrographs. Many of those Websites are interactive, with quizzes for students, including questions more of the type that they will encounter on national or course exams. Those Websites also are often streamlined to specific course content. A printed text is limited in that it cannot be modified to fit an individual course's content. In addition, the book competes with the Wheater atlas that is sold with a CD that students and faculty can use to review histology in an electronic form.

In summary, Picture Tests in Histology presents a high-quality series of micrographs that could be a useful text for students reviewing histology for exams or before studying the same regions or topics in pathology. However, the market for such books is very limited, especially when one considers the format of the questions.
Robert M. Klein
University of Kansas Medical Center
Kansas City, Kansas 